\title{
Pertinent Negatives
}

Fadwa Ahmed, BS

Warren Alpert Medical School of Brown University, Providence, RI, USA

KEY WORDS: poetry; radiology; narrative.

$\mathrm{J}$ Gen Intern Med 36(8):2463

DOI: $10.1007 / \mathrm{s} 11606-021-06767-9$

(c) Society of General Internal Medicine 2021

i.

Nana Beth is not in Church.

Her grandson finds on the bathroom floor

a puddle of Nana's own.

When we enter Nana's room

one fluorescent orange Monday

afternoon, she is not in any pain.

Except for when she breathes

in her only complaint, a sour taste

in her mouth that won't go away.

ii.

A reconstructed geometry of her abdominal geography:

a gallbladder the size of a deflated beach-ball, an incidental sliver of the potential space around the apex - it exists and it is full. Nana Beth is having a bad day - the heart swings. iii.

Nana Beth's aorta has created a second path for itself, the aortic leaflets brush and rustle, act their name for once, keep her toes warm.

Nana Beth's story bifurcates, segments of a segment sieved through two sets of holes, emplotted into two narrative coagulates, two handfuls

of clots, Nana Beth's chest rises and falls. How badly the lungs want to collapse, the chest wall to burst forth, ribs like secret petals opening to drink the orange stuff of the sun.

Corresponding Author: Fadwa Ahmed, BS; Warren Alpert Medical School of Brown University, Providence, RI 02903, USA (e-mail:fadwa_ahmed@brown.edu).

Publisher's Note: Springer Nature remains neutral with regard to jurisdictional claims in published maps and institutional affiliations. 